\title{
Poland syndrome
}

INSERM

\section{Source}

INSERM. (1999). Orphanet: an online rare disease and orphan drug data base. Poland syndrome. ORPHA:2911

Poland syndrome is marked by a unilateral absence or hypoplasia of the pectoralis major muscle (most frequently involving the sternocostal portion), and a variable degree of ipsilateral hand anomalies, including symbrachydactyly. 